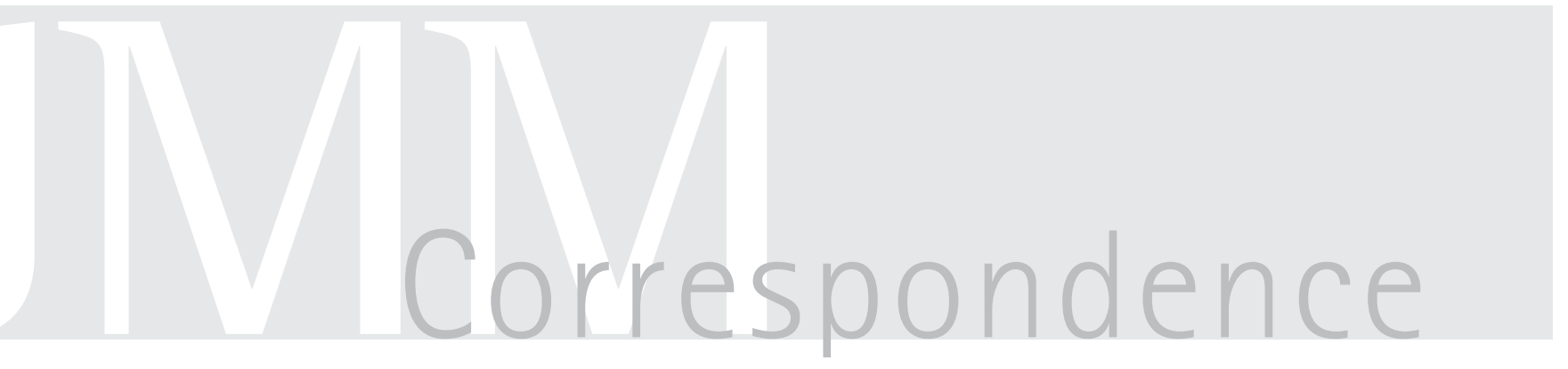

\title{
Genomovar distribution of the Burkholderia cepacia complex differs significantly between Czech and Slovak patients with cystic fibrosis
}

The morbidity and mortality rates in cystic fibrosis $(\mathrm{CF})$ patients are significantly affected by infections with organisms from the Burkholderia cepacia complex (BCC). The complex currently includes nine genomic species (genomovars): Burkholderia cepacia (genomovar I), Burkholderia multivorans (genomovar II), genomovar III (divided into two recA clusters, III-A and III-B; Mahenthiralingam et al., 2000), Burkholderia stabilis (genomovar IV), Burkholderia vietnamiensis (genomovar V), genomovar VI, Burkholderia ambifaria (genomovar VII), Burkholderia anthina (genomovar VIII) and Burkholderia pyrrocinia (genomovar IX) (Vandamme, 2002). Although all genomovars have been isolated from clinical sources, their occurrence varies significantly (Agodi et al., 2001; Speert et al., 2002), indicating the differences among the genomovars in virulence factors and in the ability of person-to-person transmissibility. Most of the virulent and epidemic strains have been identified within genomovar IIIA (Mahenthiralingam et al., 2001; Agodi et al., 2002).

We compared the BCC genomovar distribution in CF patients from the Czech Republic and CF patients from the Slovak Republic. BCC isolates from 61 Czech CF patients attending the Prague $\mathrm{CF}$ centre and from 24 Slovak CF patients attending three different Slovak CF centres were collected during the year 2001. The BCC was recovered in sputum cultures and verified by means of a nested-PCR assay (Drevinek et al., 2002). The genomovar status of BCC was then determined using a set of eight $r e c A$ gene sequence-specific PCRs distinguishing all the genomovars with the exception of $B$. anthina and B. pyrrocinia.

The BCC genomovar distribution in the Czech and Slovak CF populations is shown in Table 1. Whereas genomovar III-A was predominant in the Czech CF community (90\%), in Slovakia the most frequently identified genomovar was B. stabilis (54\%) ( $P$ of the difference $<10^{-4}$ ). This result is in marked contrast to what might be expected in two neighbouring populations which had formed the Czechoslovak federation until the end of 1992.

While the high prevalence of genomovar III-A in the Czechs has its counterparts in several Western CF populations (Canada $80 \%$, Speert et al., 2002; Italy $73 \%$, Agodi et al., 2001), the high rate of $B$. stabilis found in the CF population in Slovakia is a unique observation. Although the low numbers of patients do not permit conclusions to be drawn on the causes of this phenomenon in Slovakia, we can speculate that this may be caused either by unique strains acquired separately by each patient, or by transmission of an as yet unknown epidemic clone of $B$. stabilis. To test the hypotheses, we performed randomly amplified polymorphic DNA (RAPD) fingerprinting (Mahenthiralingam et al., 1996), a widely used genotyping method for BCC strain analyses. Thirteen Slovak
B. stabilis isolates showed patterns indistinguishable among all the isolates (data not shown). If such an RAPD result was obtained in genomovars other than B. stabilis, it would suggest clonality of the isolates. However, as genomic variability among B. stabilis strains is remarkably restricted (Vandamme et al., 2000), the result does not allow exclusion of either of the hypotheses, and further analyses to confirm or refute the relationship of the isolates are needed.

In conclusion, the difference in genomovar distribution between two closely related populations is a surprising result as is the high percentage of genomovar III-A in the Czech Republic and of B. stabilis in Slovakia.

\section{Acknowledgements}

This work was supported by grant NM/6568-3 of the Ministry of Health and by grant 111300003 of the Ministry of Education, the Czech Republic.

Pavel Drevinek, ${ }^{1}$ Ondrej Cinek, ${ }^{1}$ Jan Melter, ${ }^{2}$ Leon Langsadl, ${ }^{3}$ Yveta Navesnakova ${ }^{4}$ and Vera Vavrova ${ }^{1}$

${ }^{1}$ 2nd Medical School of Charles University, Prague, Czech Republic

${ }^{2}$ Institute for Children with Respiratory Diseases and Tuberculosis, Dolny

Smokovec, Slovak Republic

${ }^{3}$ National Institute of Tuberculosis and Respiratory Diseases, Bratislava, Slovak Republic

Table 1. Genomovar distribution of the BCC in Czech and Slovak CF patients

\begin{tabular}{|c|c|c|c|c|c|c|c|c|c|c|}
\hline \multirow[t]{2}{*}{ Country } & \multirow{2}{*}{$\begin{array}{l}\text { Total no. of } \\
\text { patients }\end{array}$} & \multicolumn{9}{|c|}{ No. of patients infected with genomovar $[n(\%)]^{\star}$} \\
\hline & & I & B. multivorans & III-A & III-B & B. stabilis & B. vietnamiensis & VI & B. ambifaria & $\begin{array}{l}\text { Unidentified } \\
\text { genomovar } \dagger\end{array}$ \\
\hline Czech Republic & $61(100 \%)$ & 0 & 3 & $55(90 \%)$ & 1 & 1 & 0 & 0 & 0 & 1 \\
\hline Slovak Republic & $24(100 \%)$ & 0 & 0 & $7(29 \%)$ & 3 & $13(54 \%)$ & 0 & 0 & 0 & 1 \\
\hline
\end{tabular}

${ }^{\star} P$ of the difference (Kolmogorov-Smirnov test) $<10^{-4}$.

$\dagger$ No genomovar-specific reaction was positive, indicating the possible presence of another genomovar from the BCC. 
${ }^{4}$ University Hospital, Kosice, Slovak Republic

Correspondence: Pavel Drevinek (pavel.drevinek@Lfmotol.cuni.cz)

Agodi, A., Mahenthiralingam, E., Barchitta, M., Giannino, V., Sciacca, A. \& Stefani, S. (2001). Burkholderia cepacia complex infection in Italian patients with cystic fibrosis: prevalence, epidemiology, and genomovar status. J Clin Microbiol 39, 2891-2896.

Agodi, A., Barchitta, M., Giannino, V. \& 8 other authors (2002). Burkholderia cepacia complex in cystic fibrosis and non-cystic fibrosis patients: identification of a cluster of epidemic lineages. J Hosp Infect 50, 188-195.

Drevinek, P., Hrbackova, H., Cinek, O., Bartosova, J., Nyc, O., Nemec, A. \& Pohunek, P. (2002). Direct PCR detection of Burkholderia cepacia complex and identification of its genomovars by using sputum as source of DNA. J Clin Microbiol 40, 3485-3488.

Mahenthiralingam, E., Campbell, M. E., Henry, D. A. \& Speert, D. P. (1996).

Epidemiology of Burkholderia cepacia infection in patients with cystic fibrosis: analysis by randomly amplified polymorphic DNA fingerprinting. J Clin Microbiol 34, 2914-2920.

Mahenthiralingam, E., Bischof, J., Byrne, S. K., Radomski, C., Davies, J. E., Av-Gay, Y. \& Vandamme, P. (2000). DNA-based diagnostic approaches for identification of Burkholderia cepacia complex, Burkholderia vietnamiensis, Burkholderia multivorans, Burkholderia stabilis, and Burkholderia cepacia genomovars I and III. J Clin Microbiol 38, 3165-3173.

Mahenthiralingam, E., Vandamme, P., Campbell, M. E. \& 7 other authors (2001).
Infection with Burkholderia cepacia complex genomovars in patients with cystic fibrosis: virulent transmissible strains of genomovar III can replace Burkholderia multivorans. Clin Infect Dis 33, 1469-1475.

Speert, D. P., Henry, D., Vandamme, P., Corey, M. \& Mahenthiralingam, E. (2002).

Epidemiology of Burkholderia cepacia complex in patients with cystic fibrosis, Canada. Emerg Infect Dis 8, 181-187.

Vandamme, P. (2002). Polyphasic taxonomy in practise: the Burkholderia cepacia challenge. WFCC Newsletter 34, 17-24.

Vandamme, P., Mahenthiralingam, E., Holmes, B., Coenye, T., Hoste, B., De Vos, P., Henry, D. \& Speert, D. P. (2000). Identification and population structure of Burkholderia stabilis sp. nov. (formerly Burkholderia cepacia genomovar IV). J Clin Microbiol 38, 10421047. 